\title{
Stress and Burnout Related to Electronic Health Record Use among Healthcare Providers during the COVID-19 Pandemic in Saudi Arabia: A Preliminary National Randomized Survey
}

\author{
Jwaher A. Almulhem ${ }^{1, *}$, Raniah N. Aldekhyyel ${ }^{1}$, Samar Binkheder ${ }^{1} \mathbb{D}$, Mohamad-Hani Temsah ${ }^{2}$ and \\ Amr Jamal ${ }^{3,4}$ (D) \\ 1 Medical Informatics and E-learning Unit, Medical Education Department, College of Medicine, King Saud \\ University, Riyadh 11362, Saudi Arabia; raldekhyyel@ksu.edu.sa (R.N.A.); sbinkheder@ksu.edu.sa (S.B.) \\ 2 Pediatric Department, College of Medicine, King Saud University, Riyadh 11362, Saudi Arabia; \\ mtemsah@ksu.edu.sa \\ 3 Evidence-Based Health Care \& Knowledge Translation Research Chair, King Saud University, \\ Riyadh 11362, Saudi Arabia; amrjamal@ksu.edu.sa \\ 4 Family \& Community Medicine Department, College of Medicine, King Saud University, \\ Riyadh 11362, Saudi Arabia \\ * Correspondence: Jalmulhem@ksu.edu.sa; Tel.: +966-118-066-385
}

check for updates

Citation: Almulhem, J.A.;

Aldekhyyel, R.N.; Binkheder, S.; Temsah, M.-H.; Jamal, A. Stress and Burnout Related to Electronic Health Record Use among Healthcare Providers during the COVID-19 Pandemic in Saudi Arabia: A Preliminary National Randomized Survey. Healthcare 2021, 9, 1367 https://doi.org/10.3390/ healthcare 9101367

Academic Editors: Victor Kallen and Daniele Giansanti

Received: 20 August 2021

Accepted: 11 October 2021

Published: 14 October 2021

Publisher's Note: MDPI stays neutral with regard to jurisdictional claims in published maps and institutional affiliations.

Copyright: (c) 2021 by the authors. Licensee MDPI, Basel, Switzerland. This article is an open access article distributed under the terms and conditions of the Creative Commons Attribution (CC BY) license (https:// creativecommons.org/licenses/by/ $4.0 /)$.

\begin{abstract}
Healthcare providers' burnout may potentially have a negative impact on patient care The use of the electronic health record (EHR) increases the burden for healthcare providers (HCPs), particularly during the coronavirus disease-2019 (COVID-19) pandemic. This study assessed the stress and burnout related to the use of EHRs and health information technology (HIT) tools among HCPs during COVID-19 in Saudi Arabia. We used a self-developed survey tool. It consisted of five sections; demographics and professional data, experience using EHR, effects of EHR use, use of EHR and technology tools during COVID-19, and health and wellbeing. The survey link was emailed to a random sample of HCPs registered with a national scientific regulatory body. Univariate, bivariate, and multivariate analyses were performed to measure the association between burnout and study variables. A total of 182 participants completed the survey. $50.5 \%$ of participants reported a presence of HIT-related stress, and $40.1 \%$ reported a presence of burnout. The variables independently associated with burnout were providing tertiary level of care, working with COVID-19 suspected cases, dissatisfaction with EHRs, and agreement with the statement that using EHRs added frustration to the workday. Further research that explores possible solutions is warranted to minimize burnout among HCPs, especially during infectious outbreaks.
\end{abstract}

Keywords: electronic health record; burnout; COVID-19; healthcare providers; Saudi Arabia

\section{Introduction}

With the global spread of the novel coronavirus disease-2019 (COVID-19), the use of technology to support patient care has seen a rapid rise. Technological tools were used to support patient care during the COVID-19 pandemic crisis through early detection of suspected individuals with the virus using artificial intelligence [1,2], generating big data analytics, reporting real-time data [3], and providing virtual care to patients [4]. The use of electronic health records (EHRs) to support patient care during COVID-19 has also been a focus of many healthcare organizations [5]. The EHR effectively handled COVID-19 by including standardized triage systems, enhancing ordering tools, securing communication tools, automating reporting and analysis, and providing telemedicine consultations, and patient portal services [5].

Despite the advantages of using EHRs in healthcare organizations as a tool to manage the COVID-19 outbreak [5], many healthcare providers (HCPs) reported an increased burden, burnout, and work dissatisfaction related to using EHR systems [6,7]. COVID-19 
has led to increased levels of anxiety, stress, and psychological burdens reported by HCPs, especially in the acute care settings and frontlines $[1,8,9]$. In addition, burnout was reported as a leading factor for many HCPs to leave their jobs [10], and reduce their productivity levels [11], which causes significant disruption to healthcare services [10]. The Agency for Healthcare and Quality (AHRQ) defines burnout as a "long-term stress reaction marked by emotional exhaustion, depersonalization, and a lack of sense of personal accomplishment." The AHRQ published five reasons that contribute to HCPs' burnout, one of which is the use of EHRs [12].

In Saudi Arabia, as of 10 August 2021, the total number of cases reported was 534,312, with 8311 deaths [13]. During April 2021, the number of COVID-19 cases increased significantly, indicating a second pandemic wave [14]. Researchers reported that the prevalence of burnout among HCPs in Saudi Arabia during COVID-19 was 75\% [15]. In response, the Saudi Commission for Health Specialties (SCFHS); a national regulatory independent professional and scientific body responsible for healthcare practitioners' training, classification, and registration [16] developed a national support program, called "Daem," meaning "The Supporter". The program is designed to provide online interactive guidance services for HCPs who experience professional burnout during COVID-19 [17].

Using EHRs might be a significant factor causing burnout [18] by creating an additional burden on HCPs responsible for performing additional tasks during clinical encounters. Kroth et al. [19] hypothesized that "EHR-associated stress adds to the overall stress and could lead to burnout, which may play a role in the quality of patient care". New tasks were introduced to the traditional clinical workflow with EHR use, such as medication reconciliation and computerized physician order entry (CPOE) [20]. However, during COVID-19, additional tasks became required from HCPs, such as virtual consultations with patients [5,21], secured messaging with clinical teams and patients [5], and the use of e-prescriptions [21]. Such technology-related tasks increased clinicians' workload, contributing to an increased risk of HCPs' burnout and stress [19]. Esmaeilzadeh and Mirzaei specifically studied how the use of EHR features affects HCPs' burnout among providers who cared for confirmed COVID-19 patients. The researchers concluded that the more that the HCPs were concerned about COVID-19, the higher the odds of burnout [22]. The increased reliance on EHR and other technology-based tools during COVID-19 has led many HCPs to rapidly acquire and practice new skills to provide patient care $[4,21,23]$.

To quantify the association between health information technology (HIT)-related stress and burnout, Gardner et al. in 2019 reported that $26 \%$ of 4197 surveyed physicians in the United States (U.S.) reported burnout, and $64.2 \%$ agreed that EHR adds to their frustration [18]. Other reported symptoms associated with stress, which were related to the presence of HIT were insufficient time for documentation [18], and excessive time spent on EHR after work hours $[18,24,25]$. In another similar study conducted by Kroth et al., they reported $43 \%$ of surveyed clinicians experienced symptoms of burnout. In addition, the researchers found a significant relationship between the EHR design and physician stress and reported causes of burnout due to how information was presented within the EHR [19]. During COVID-19, Esmaeilzadeh and Mirzaei reported that $36 \%$ of HCPs had at least one symptom of burnout. Additional HIT-related stress factors identified were insufficient EHR training, and increased automation systems at work [22].

HCPs' burnout caused by EHR use can vary across different countries. For example, for the same EHR vendor software "Epic Systems" ${ }^{\circledR}$, physicians in Australia reported satisfaction compared to physicians in the U.S. due to the countries' variations of regulations and clinical documentation requirements [10]. While the effectiveness of using EHRs was demonstrated in several studies within Saudi Arabia [23,26], little is known about the side effects and burden of using these systems among HCPs during COVID-19 [27].

The importance of measuring and reporting the current state of satisfaction and how it may impact feelings of stress and burnout among HCPs in Saudi Arabia may potentially assist in improving the system design, decrease HCPs' burnout, and increase satisfaction, especially during the COVID-19 pandemic. Without particular studies that measure the 
level of HCPs' burnout from using the EHRs, we are unable to understand the underlying reasons for HCPs' burnout, improve the system features, and enhance supporting policies. While some studies measured the effective use of other technology tools during COVID$19[21,23,26]$, to our knowledge, no study has assessed the burden related to the use of EHRs and other HIT tools during the COVID-19 pandemic among HCPs in our region. Therefore, our aim was to assess stress and burnout related to the use of EHRs and other HIT tools among HCPs during COVID-19 in Saudi Arabia.

\section{Materials and Methods}

\subsection{Survey Development}

We used a self-developed survey instrument that was constructed based on reviewing several studies related to burnout, EHRs, and COVID-19 [9,18,20,28-30]. Before distributing the survey, we conducted a pilot study [31] by asking 37 HCPs, representing different specialties, to review the instrument and test the feasibility of the study. Based on the feedback received, a few wording issues and answer options were modified. The final survey instrument consisted of five sections with a total of 35 questions: (1) demographics and professional data, (2) experience using EHR systems, (3) effects of EHR use, (4) use of EHRs features and technology tools during COVID-19, and (5) health and wellbeing (Appendix A). The questions were developed in several formats: closed-ended, 5-point Likert scale, and binary "yes" and "no" questions. Section five that measured HIT-related stress included three questions (sufficiency of time for documentation at work, the amount of time spent using the EHR remotely at home, and does the use of EHR add frustration) used by Haskell J, et al. [18] to measure HIT-related stress adapted from the Mini z Burnout Survey [28]. Section 5 also measured self-perception of burnout using a single reliable item developed by Schmoldt et al. [29] and validated among HCPs [30], which consisted of a 5-point Likert scale identifying symptoms of burnout among participants. To identify if the burnout resulting from EHR use has increased during the pandemic, we asked the participants about their perceptions of burnout (Appendix A).

\subsection{Survey Distribution}

We used the SCFHS email database to distribute the survey [16]. The survey invitation including the purpose of the study with a link to the web-based survey was emailed to a random sample of 10,000 HCPs registered at the SCFHS. Self-identifying practicing HCPs who use the EHR at their respective workplaces were eligible for the study. Our study excluded interns, medical students, and HCPs who do not use EHRs in their workplace. The survey was open for nine months with reminder emails sent two weeks after the first invitation.

This study was approved by the Institutional Review Board at King Saud University, College of Medicine (IRB\# E-3-20-4938).

\subsection{Statistical Analysis}

We used SPSS 19 software to produce descriptive statistics, covering demographic and professional characteristics, HIT characteristics, burnout, technology tools used during COVID-19, and participants' perception regarding burnout associated with EHR use during COVID-19. For analysis purposes and due to the close response percentages, we combined responses of 5-point Likert scales into three categories [18].

Our two main variables are burnout and HIT- related stress. We determined the presence of HIT-related stress if one or more of the following response categories were indicated: (1) agree/strongly agree that EHRs add to the frustration of the workday, (2) moderately high/excessive use of the EHR at home, and/or (3) poor/marginal time for documentation [18]. To determine burnout among our sample, participants who had $<2$ on the 5-point scale were defined as "do not have symptoms of burnout," while participants who had $>3$ on the 5-point scale were recognized as "having one or more symptoms of burnout" [18]. 
To measure the association between burnout and demographic, professional, and HIT characteristics among participants, we calculated odds ratio (OR) in unadjusted and adjusted logistic regression models [18,22,32]. Logistic regression is used to measure the association of one or more independent (predictor) variables with a binary dependent (outcome) variable. The strength of the association is measured by reporting OR [33]. The independent variables in our study were demographic, professional, and HIT characteristics, while the dependent variable was presence of burnout. The univariate logistic regression model includes only one predictor, which is reported by the unadjusted OR. The multivariate logistic regression includes more than one predictor variables, which are reported by the adjusted ORs. We only presented the significant variables found in the unadjusted simple logistic regression model for the multivariate regression model. The significance level was assessed at 0.05 .

\section{Results}

A total of 182 participants completed the survey. We could not calculate the response rate due to our inability to determine which emails were up-to-date and delivered to the inboxes of HCPs. More than half of the participants were younger than 45 years, male, married, and non-Saudi (Table 1). Most of the participants were physicians working in governmental hospitals providing tertiary care with average reported working hours between 40 to $49 \mathrm{~h}$ per week. A total of 72 (40\%) participants provided clinical care to COVID-19 suspected patients. The average number of on-calls was 2.34 per week. Participants indicated an average of around 6 years using EHRs. Among our participants, 113 (62.1\%) physicians completed the survey, with 26 (14.3\%) specialized in internal medicine and 70 $(38.5 \%)$ were consultants (Table 1$)$.

Table 1. Participants' demographic and professional characteristics $(\mathrm{N}=182)$.

\begin{tabular}{lc}
\hline \multicolumn{1}{c}{ Characteristic } & $\mathbf{N}(\%)$ \\
\hline Age (years) & $106(58.2)$ \\
$\leq 45$ & $70(38.5)$ \\
$46-65$ & $6(3.3)$ \\
$>65$ & \\
Gender & $108(59.3)$ \\
$\quad$ Male & $74(40.7)$ \\
Female & \\
Marital status & $34(18.7)$ \\
Single & $141(77.5)$ \\
Married & $7(3.8)$ \\
Widowed or Divorced & \\
Nationality & $82(45.1)$ \\
Saudi & $100(54.1)$ \\
Non-Saudi & \\
Healthcare organization type & $141(77.5)$ \\
Governmental & $40(22)$ \\
Private & \\
level of care & $35(19.2)$ \\
Primary & $45(24.7)$ \\
Secondary & $102(56)$ \\
Tertiary & \\
Healthcare profession & $113(62.1)$ \\
Physician & \\
\hline
\end{tabular}


Table 1. Cont.

\begin{tabular}{|c|c|}
\hline Characteristic & $\mathbf{N}(\%)$ \\
\hline \multicolumn{2}{|l|}{ Specialty ${ }^{1}$} \\
\hline Anesthesiology & $8(4.4)$ \\
\hline Family Medicine & $5(2.7)$ \\
\hline Internal Medicine & $26(14.3)$ \\
\hline Obstetrics/Gynecology & $3(1.6)$ \\
\hline ENT & $6(3.3)$ \\
\hline Pediatrics & $18(9.9)$ \\
\hline Radiology & $8(4.4)$ \\
\hline Surgery & $21(11.5)$ \\
\hline Other & $18(9.9)$ \\
\hline \multicolumn{2}{|l|}{ Job title ${ }^{1,2}$} \\
\hline Resident & $12(6.6)$ \\
\hline Registrar/Senior Registrar & $31(17.0)$ \\
\hline Consultant & $70(38.5)$ \\
\hline Nurse & $44(24.2)$ \\
\hline Pharmacist & $9(4.9)$ \\
\hline Other ${ }^{3}$ & $16(8.8)$ \\
\hline \multicolumn{2}{|l|}{ Average working hours per week } \\
\hline$<40$ & $19(10.4)$ \\
\hline $40-49$ & $113(62.1)$ \\
\hline $50-59$ & $23(12.6)$ \\
\hline$\geq 60$ & $27(14.8)$ \\
\hline \multicolumn{2}{|l|}{ Providing care to COVID-19 } \\
\hline Yes, with COVID-19 suspected & $72(39.6)$ \\
\hline Yes, with COVID-19 confirmed & $46(25.3)$ \\
\hline No & $64(35.2)$ \\
\hline Number of nights on call per week ${ }^{4}$ & $2.34(3.351)$ \\
\hline Years of using EHR ${ }^{4}$ & $6.10(4.422)$ \\
\hline
\end{tabular}

${ }^{1}$ Physicians' other professional characteristics $(\mathrm{N}=113) .{ }^{2}$ Based on SCFHS categorization. ${ }^{3}$ Other professions include mostly technicians and dentists. ${ }^{4}$ Presented as Mean (M) and Standard Division (SD).

When asked about the level of satisfaction with EHR, 107 (58.8\%) participants were either satisfied or very satisfied. A total of 151 out of $182(83 \%)$ participants indicated that in general they did not have access to the EHR from home prior to the COVID-19 pandemic. Among those with access to the EHR from home, 20 out of 31 (64.5\%) participants indicated an opportunity to work from home. Regarding the impact of EHR on workflow, more than $60 \%$ of participants either agreed or strongly agreed that EHR systems improve communication, enhance patients care and improve patient safety. Furthermore, more than $50 \%$ of the participants felt that EHR systems improve their job satisfaction and clinical workflow (Table 2). Regarding the use of technology during the COVID-19 pandemic, 130 $(70 \%)$ of participants used e-prescription, followed by the use of messaging communication tools $112(61.5 \%)$. The least electronic feature used by participants was the EHR remote access 59 (32.4\%) (Figure 1).

A total of $110(60 \%)$ of participants agreed that using shared computer peripheral devices causes fear in becoming infected with the COVID-19, while 94 (51.6\%) of participants slightly or moderately reported that the burnout they experience from the use of EHRs and its associated features has increased due to the COVID-19 pandemic (Figure 2). 
Table 2. HIT characteristics among participants $(\mathrm{N}=182)$.

\begin{tabular}{|c|c|}
\hline Characteristic & $\mathbf{N}(\%)$ \\
\hline \multicolumn{2}{|l|}{ Satisfaction with the EHR system } \\
\hline Very dissatisfied/Dissatisfied & $40(22.0)$ \\
\hline Neither satisfied nor dissatisfied & $35(19.2)$ \\
\hline Satisfied/Very satisfied & $107(58.8)$ \\
\hline \multicolumn{2}{|l|}{ EHR remote access from home } \\
\hline Yes & $31(17)$ \\
\hline No & $151(83)$ \\
\hline \multicolumn{2}{|l|}{ Reason for remote EHR use } \\
\hline $\begin{array}{l}\text { Unable to complete work during regular } \\
\text { work hours }\end{array}$ & $3(9.7)$ \\
\hline Have the opportunity to work from home & $20(64.5)$ \\
\hline Both the reason & $2(6.5)$ \\
\hline Other & $6(19.4)$ \\
\hline \multicolumn{2}{|l|}{ Impact of EHR on workflow } \\
\hline \multicolumn{2}{|l|}{ EHR improves communication } \\
\hline Agree/Strongly agree & $112(61.5)$ \\
\hline Neither agree nor disagree & $37(20.3)$ \\
\hline Strongly disagree/Disagree & $33(18.1)$ \\
\hline \multicolumn{2}{|l|}{ EHR use improves patient care } \\
\hline Agree/Strongly agree & $115(63.2)$ \\
\hline Neither agree nor disagree & $32(17.6)$ \\
\hline Strongly disagree/Disagree & $35(19.2)$ \\
\hline \multicolumn{2}{|l|}{ EHR use improves job satisfaction } \\
\hline Agree/Strongly agree & $108(59.3)$ \\
\hline Neither agree nor disagree & $34(18.7)$ \\
\hline Strongly disagree/Disagree & $40(22)$ \\
\hline \multicolumn{2}{|l|}{ EHR use improves clinical workflow } \\
\hline Agree/Strongly agree & $109(59.9)$ \\
\hline Neither agree nor disagree & $33(18.1)$ \\
\hline Strongly disagree/Disagree & $40(22.0)$ \\
\hline \multicolumn{2}{|l|}{ EHR use improve patient safety } \\
\hline Agree/Strongly agree & $115(63.2)$ \\
\hline Neither agree nor disagree & $38(20.9)$ \\
\hline Strongly disagree/Disagree & $29(15.9)$ \\
\hline \multicolumn{2}{|l|}{ HIT-related stress measures } \\
\hline \multicolumn{2}{|l|}{$\begin{array}{l}\text { The amount of time spends using the EHR at } \\
\text { home }\end{array}$} \\
\hline Minimal/none & $113(62.1)$ \\
\hline Modest/Satisfactory & $50(27.5)$ \\
\hline Moderately high/Excessive & $19(10.4)$ \\
\hline \multicolumn{2}{|l|}{$\begin{array}{l}\text { Sufficiency of time for documentation at } \\
\text { work }\end{array}$} \\
\hline Poor/Marginal & $61(33.5)$ \\
\hline Satisfactory/Good & $111(61)$ \\
\hline Optimal & $10(5.5)$ \\
\hline \multicolumn{2}{|l|}{ Using the EHR adds frustration to my day } \\
\hline Agree/Strongly agree & $62(34.1)$ \\
\hline Neither agree nor disagree & $52(28.6)$ \\
\hline Strongly disagree/Disagree & $68(37.4)$ \\
\hline Presence of HIT-related stress 1 & $92(50.5)$ \\
\hline \multicolumn{2}{|l|}{ My proficiency in EHR use } \\
\hline Poor/Marginal & $22(12.1)$ \\
\hline Satisfactory/Good & $136(74.7)$ \\
\hline Optimal & $24(13.2)$ \\
\hline
\end{tabular}

1 HIT-related stress to be present if one or more of the following response categories were indicated: (1) agree/strongly agree that EHRs add to the frustration of their day, (2) moderately high/excessive use of the EHR at home, and (3) poor/marginal time for documentation. 


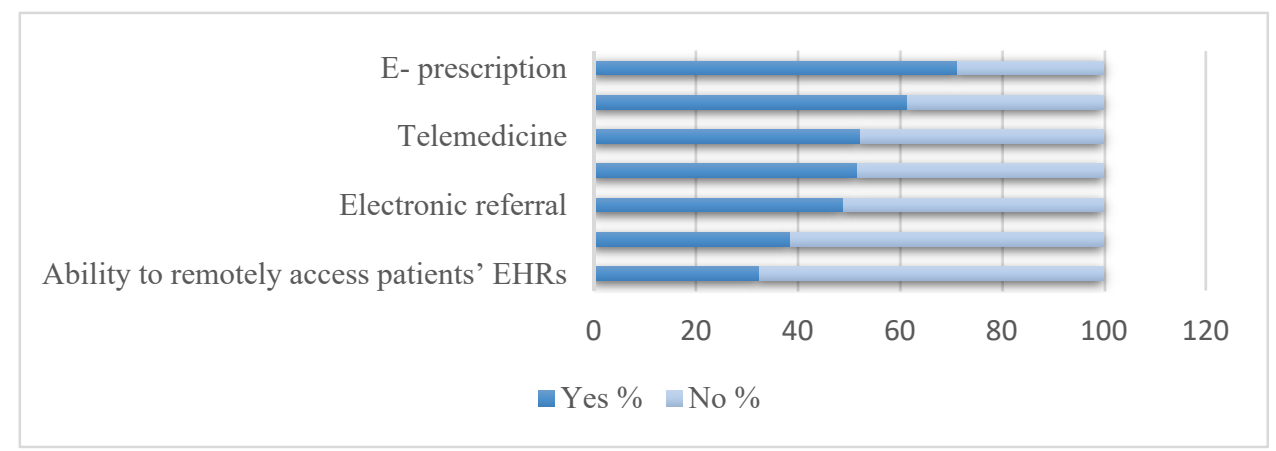

Figure 1. Use of EHR associated features during COVID 19 among participants.

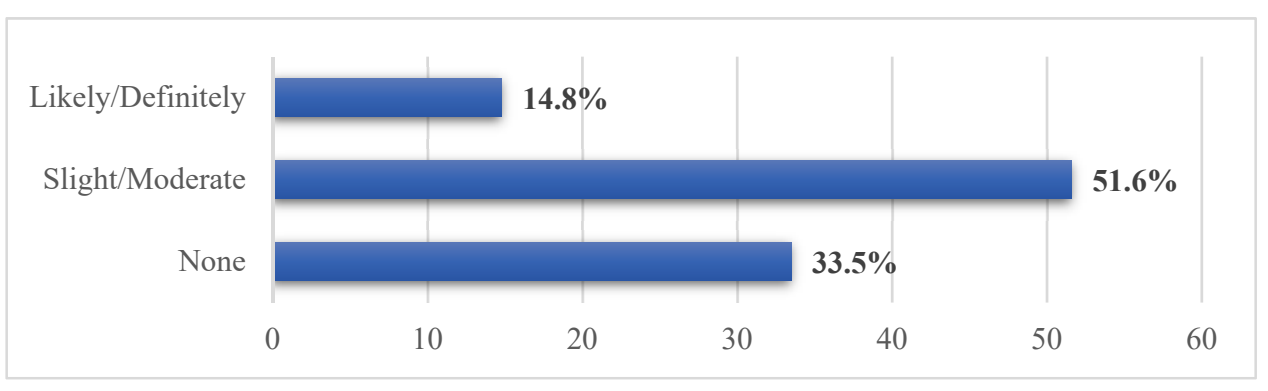

Figure 2. Participants' perception regarding burnout they experience from the use of EHR and its associated features due to the COVID-19 pandemic.

In regard to HIT-related stress, 92 (50.5\%) of participants reported the presence of HIT-related stress. When participants were asked to determine which measures specifically contributed to HIT-related stress, 62 (34.1\%) of participants either agreed or strongly agreed that using the EHR adds frustration to their day. A total of 136 (74.7\%) participants reported their proficiency in EHR use as satisfactory or good (Table 2). Due to the low number of physicians among each specialty, we did not report HIT-related stress measures based on physicians' specialty.

Regarding burnout, 73 (40.1\%) of participants reported the presence of burnout, with $37(50 \%)$ identifying as physicians. (Table 3$)$.

Table 3. Burnout among participants $(\mathrm{N}=182)$.

\begin{tabular}{lc}
\hline \multicolumn{1}{c}{ Characteristic } & N (\%) \\
\hline Presence of burnout ${ }^{\mathbf{1}}$ & \\
Yes & $73(40.1)$ \\
No & $109(59.9)$ \\
Healthcare profession & \\
Physician & $37(50.6)$ \\
Nurse & $24(32.9)$ \\
Pharmacists & $7(9.9)$ \\
Other & $5(6.8)$ \\
\hline
\end{tabular}
${ }^{1}$ Burnout measure was dichotomized into "no presence of burnout" (1 or 2 on a 5-point scale) and "presence of
burnout" $3-5$ on a 5-point scale).

In the unadjusted model, the following seven variables were significantly associated with the presence of burnout: female gender, tertiary level of care, physician as a health care profession, working with both suspected and confirmed COVID-19 cases, neither satisfied nor dissatisfied and very dissatisfied or dissatisfied with EHR, participants who think or may think that sharing computer peripherals causes fear in becoming infected with the COVID-19, and agreement about using the EHR adds frustration to daily work (Table 4). 
Table 4. Estimate of the association between demographic, professional, and HIT characteristics and burnout among participants $(\mathrm{N}=182)$.

\begin{tabular}{|c|c|c|c|c|}
\hline Characteristic & $\begin{array}{c}\text { Unadjusted OR } \\
1_{(95 \% C I)}\end{array}$ & $p$-Value & $\begin{array}{l}\text { Adjusted OR }{ }^{2} \\
(95 \% \mathrm{CI})\end{array}$ & $p$-Value \\
\hline \multicolumn{5}{|l|}{ Gender } \\
\hline Male & ref & & ref & \\
\hline Female & $\begin{array}{c}2.674 \\
(1.447-4.939)\end{array}$ & $0.002^{3}$ & $\begin{array}{c}2.153 \\
(0.936-4.952)\end{array}$ & 0.071 \\
\hline \multicolumn{5}{|l|}{ Level of care } \\
\hline Primary & ref & & ref & \\
\hline Secondary & $\begin{array}{c}1.594 \\
(0.602-4.218)\end{array}$ & 0.348 & $\begin{array}{c}2.899 \\
(0.804-10.447)\end{array}$ & 0.104 \\
\hline Tertiary & $\begin{array}{c}2.568 \\
(1.095-6.019)\end{array}$ & $0.030^{3}$ & $\begin{array}{c}5.077 \\
(1.557-16.550)\end{array}$ & $0.007^{3}$ \\
\hline \multicolumn{5}{|l|}{ Healthcare profession } \\
\hline Physician & $\begin{array}{c}0.406 \\
(0.199-0.827)\end{array}$ & $0.013^{3}$ & $\begin{array}{c}0.450 \\
(0.163-1.246)\end{array}$ & 0.124 \\
\hline Nurse & ref & & ref & \\
\hline Pharmacist & $\begin{array}{c}2.917 \\
(0.544-15.646)\end{array}$ & 0.212 & $\begin{array}{c}9.231 \\
(0.934-91.251)\end{array}$ & 0.057 \\
\hline Other & $\begin{array}{c}0.379 \\
(0.113-1.273)\end{array}$ & 0.117 & $\begin{array}{c}0.534 \\
(0.127-2.240)\end{array}$ & 0.391 \\
\hline \multicolumn{5}{|l|}{ Providing care to COVID-19 } \\
\hline $\begin{array}{l}\text { Yes, with COVID-19 } \\
\text { suspected }\end{array}$ & $\begin{array}{c}2.684 \\
(1.292-5.575)\end{array}$ & $0.008^{3}$ & $\begin{array}{c}4.059 \\
(1.592-10.345)\end{array}$ & $0.003^{3}$ \\
\hline $\begin{array}{l}\text { Yes, with COVID-19 } \\
\text { confirmed } \\
\text { No }\end{array}$ & $\begin{array}{l}3.000 \\
(1.336-6.736) \\
\text { ref }\end{array}$ & $0.008^{3}$ & $\begin{array}{c}2.186 \\
(0.822-5.814) \\
\text { ref }\end{array}$ & 0.117 \\
\hline \multicolumn{5}{|l|}{ EHR satisfaction } \\
\hline $\begin{array}{l}\text { Very } \\
\text { dissatisfied/Dissatisfied }\end{array}$ & $\begin{array}{c}2.373 \\
(1.130-4.984)\end{array}$ & $0.022^{3}$ & $\begin{array}{c}3.245 \\
(1.252-8.414)\end{array}$ & $0.015^{3}$ \\
\hline $\begin{array}{l}\text { Neither satisfied nor } \\
\text { dissatisfied } \\
\text { Satisfied/Very satisfied }\end{array}$ & $\begin{array}{c}2.273 \\
(1.044-4.948) \\
\text { ref }\end{array}$ & $0.039^{3}$ & $\begin{array}{c}0.958 \\
(0.359-2.559) \\
\text { ref }\end{array}$ & 0.932 \\
\hline \multicolumn{5}{|l|}{ Use shared computers } \\
\hline Yes & $\begin{array}{c}3.692 \\
(1.016-13.418)\end{array}$ & $0.047^{3}$ & $\begin{array}{c}2.111 \\
(0.489-9.113)\end{array}$ & 0.317 \\
\hline No & ref & & ref & \\
\hline Maybe & $\begin{array}{c}4.938 \\
(1.283-19.007)\end{array}$ & $0.020^{3}$ & $\begin{array}{c}4.270 \\
(0.909-20.054)\end{array}$ & 0.066 \\
\hline \multicolumn{5}{|c|}{ Using the EHR adds frustration to my day } \\
\hline $\begin{array}{l}\text { Strongly disagree or } \\
\text { Disagree }\end{array}$ & ref & & ref & \\
\hline $\begin{array}{l}\text { Neither agree nor } \\
\text { disagree }\end{array}$ & $\begin{array}{c}1.599 \\
(0.733-3.490)\end{array}$ & 0.238 & $\begin{array}{c}2.505 \\
(0.944-6.647)\end{array}$ & 0.065 \\
\hline Strongly agree or Agree & $\begin{array}{c}3.846 \\
(1.839-8.045)\end{array}$ & $0.000^{3}$ & $\begin{array}{c}5.569 \\
(2.159-14.366)\end{array}$ & $0.000^{3}$ \\
\hline
\end{tabular}

${ }^{1}$ Only correlated variables are presented. ${ }^{2}$ Variables included in adjusted OR are gender, level of care, the healthcare profession, dealing with COVID-19, satisfaction with EHR, use shared computers and using the EHR adds frustration to my day. ${ }^{3} p<0.05$.

In the adjusted model, which included only variables significantly associated with burnout in the unadjusted model, the variables that remained independently associated with burnout were four variables; tertiary level of care, working with COVID-19 suspected cases, very dissatisfied or dissatisfied with EHR, and agreement with the statement that using the EHR adds frustration to the workday. Working in tertiary healthcare organizations was associated with 5.077 times the odds of burnout compared to working in primary healthcare organizations (AOR 5.077, 95\% CI 1.557 to 16.550). Providing care to suspected COVID-19 cases was associated with 4.059 times the odds of burnout compared to pro- 
viding care to non-COVID-19 cases (AOR 4.059, 95\% CI 1.592 to 10.345). Dissatisfaction with EHR was associated with 3.245 times the odds of burnout (AOR 3.245, 95\% CI 1.252 to 8.414). Lastly, agreeing that the EHR adds to daily frustration was associated with higher odds of burnout than neither agreement nor disagreement and disagreement with the statement (AOR 5.569, 95\% CI 2.159 to 14.366) (Table 4).

\section{Discussion}

Our objective was to measure the presence of stress and burnout among HCPs from using EHRs and HIT tools during the COVID-19 pandemic. It is critical to develop methods to measure and report levels of stress and burnout from using EHR systems on a national level, representing different healthcare sectors in the country. Our findings demonstrated variability in the demographics of our participants and their reported levels of stress and burnout. Our study is relevant to the current global effects of the pandemic on HCPs and their daily use of technology in providing patient care within the Saudi context. Results from our study add to a growing body of evidence calling for a focus on measuring the effects of technology used by HCPs and its impact on stress and burnout $[18,22,34,35]$.

Although overall satisfaction with EHRs among our participants was relatively high, HIT-related stress and burnout reports were found. Half of our participants reported HITrelated stress, with slightly half reporting burnout. These results were consistent with what has been reported previously by other researchers $[18,19,22,36]$. In addition, more than half moderately reported that the burnout they experience from EHRs and their associated features has increased due to the COVID-19 pandemic. Several predictors were associated with HCPs' burnout. In particular, participants who provided care to suspected COVID-19 patients, and providing tertiary level of care. Furthermore, our study identified several predictors related to EHR, which contribute to increased odds of burnout; dissatisfaction with EHR, and feeling that EHRs add to daily frustration. Thus, HCPs who were not satisfied with EHRs were more likely to experience burnout compared to HCPs who were satisfied with EHRs. Similarly, HCPs who felt that EHRs add to daily frustration were more likely to experience burnout compared with HCPs who did not report frustration.

During the COVID-19 pandemic, many participants believed that the use of EHRs adds frustration to their daily tasks, which increases their burnout [37]. Most participants reported a higher tendency of using e-prescriptions followed by messaging communication tools such as SMS or WhatsApp. While working on e-prescriptions was found to be time-consuming [38], it is essential to develop EHR tasks, which support clinical processes and automation, such as the use of machine learning and artificial intelligence [38]. Providing EHR customization and one-to-one training sessions are examples of suggested strategies to improve reported burnout among HCPs using EHR tools [22,39,40]. While using the EHR remote access feature was not common among our participants before the pandemic, accessing EHRs remotely has been increased during the pandemic. Indeed, the number of HCPs working from home has increased with the pandemic. Their work from home involved several duties such as providing virtual consultations and clinical advice, conducting virtual triage, and providing virtual prescriptions [41].

Safety concerns about the fear of the spread of COVID-19 were linked to burnout among participants. More than half of the participants were concerned when dealing with shared devices, e.g., computers and tablets, within the hospital during COVID-19. In addition, caring for suspected COVID-19 cases was associated with higher burnout rates among participants than providing care to non-COVID-19 cases. This reflects that participants were concerned about themselves and their families' safety [36], which was in line with studies reporting fear of being infected was a leading risk factor of anxiety and depression in the workplace $[42,43]$. These safety concerns need to be addressed to decrease burnout experience among HCPs by providing a safe hospital environment, safety training, and developing up-to-date safety guidelines and protocols [36]. These solutions might help decrease the chances of burnout due to safety concerns but may not necessarily work for all HCPs [43]. As the pandemic evolved, healthcare institutions need to develop 
an integrated psychological response for HCPs with the occupational and psychological challenge of MERS-CoV outbreaks, especially that anxiety over COVID-19 may increase during the pandemic [44-46]. It is vital that healthcare facilities provide more monitoring for burnout and enhance emotional and psychological support for all HCPs [47].

Working in a tertiary healthcare organization was associated with more burnout as compared to working in a primary healthcare organization. This may be due to the type of patients seen at tertiary healthcare organizations, i.e., more specialized, and more complicated cases. Such factors should be considered by tertiary hospitals administration to improve HCPs' wellbeing. Several interventions to decrease burnout might be used during this pandemic, such as increasing medical resources, recruiting additional HCPs, benefiting from telemedicine, and reducing excessive working hours [48].

The stress and burnout were measurable and prevalent among our participants. Specifically, physicians working with EHRs in our sample reported levels of HIT-related stress, particularly those reporting frustration with the use of EHR. Despite that, previous studies showed variations across medical specialties regarding the presence of HIT-related stress. Our findings may not be able to reflect the actual differences in specialty due to the limited number of participants. It is worth exploring the relationship between specialty and burnout on a larger sample to compare the results with other reports, which measured the levels of stress and burnout among specialists during COVID-19, such as the Medscape National Physician Burnout \& Suicide Report 2021 [49].

Future studies to explore the HCPs' burnout and HIT-related stress during the evolving COVID-19 pandemic are warranted. Other research should also examine strategically possible coping solutions that might reduce burnout and HIT-related stress by focusing on enhancing EHRs satisfaction.

Three issues may affect the generalizability of our study. First, we relied on only one distribution method, SCFHS's email database, to distribute the survey nationally. Although we used different approaches to increase responses, e.g., sending two reminders to HCPs and allowing responses to be anonymous, the responses to our survey were still low. Distributing the survey was at the peak of the pandemic in Saudi Arabia [13] with a long data collection period, which may also be related to inadequate responses among HCPs. Other methods such as social media announcements need to be employed to increase participation in future research. Second, we used one method to capture the perceived stress and burnout related to the use of EHRs during the COVID-19 pandemic as reported by our participants. Other additional methods for measuring stress and burnout related to the use of EHRs, e.g., conducting an observational study and analyzing actual EHR data, may support our study's findings. Lastly, most of our participants were physicians. Their experiences may not be generalizable to other HCPs. Focusing on other HCPs, e.g., nurses and pharmacists, would potentially explore other dimensions.

\section{Conclusions}

Although our survey response rate was low, our study demonstrated that HIT-related stress, especially the feeling that the use of EHRs adds frustration to the daily work, was a predictor for burnout among HCPs. Working in tertiary hospitals and working with COVID-19-suspected cases were also predictive factors of burnout. Further research that explores possible solutions is warranted to minimize stress and burnout among HCPs, especially during the infectious disease outbreak.

Author Contributions: Conceptualization, J.A.A.; Formal analysis, J.A.A. and A.J.; Methodology, J.A.A., R.N.A., S.B., M.-H.T. and A.J.; Supervision, J.A.A.; Writing-original draft, J.A.A., R.N.A. and S.B.; Writing-review \& editing, J.A.A., R.N.A., S.B., M.-H.T. and A.J. All authors have read and agreed to the published version of the manuscript.

Funding: This research received no external funding. 
Institutional Review Board Statement: The study was conducted according to the guidelines of the Declaration of Helsinki, and approved by the Institutional Review Board of King Saud University, College of Medicine (IRB\# E-3-20-4938 and 12.05.2020).

Informed Consent Statement: Informed consent was obtained from all subjects involved in the study.

Data Availability Statement: Not applicable.

Acknowledgments: The authors would like to thank Saudi Commission for Health Specialties for facilitating the data collection process. The authors thank King Saud University for their technical and scientific support.

Conflicts of Interest: The authors declare no conflict of interest.

\section{Appendix A. The Distributed Survey}

Dear Participant,

The purpose of this online survey is to learn how healthcare practitioners perceive the use of electronic health records (EHRs) and other technological tools and their impact on stress during the COVID 19 pandemic. This study is approved by King Saud University College of Medicine IRB (Project No. E-3-20-4938). The targeted sample is healthcare practitioners who use EHR and provide direct patient care. It will take approximately 10-15 min to answer this survey.

Your answers are confidential, surveys will be de-identified, and results will only be reported as aggregate data. Please feel free to contact the principle investigator, email:

jalmulhem@ksu.edu.sa

to answer your questions.

If you are willing to participate in this online survey, please click "Next" to begin.

Thank you for participating!

Research team:

Dr. Jwaher Almulhem

Dr. Raniah Aldekhyyel

Dr. Samar Binkheder

Dr. Amr Jamal

Dr. Mohamad-Hani Temsah

King Saud University

\section{Inclusion Criteria:}

1. Do you provide direct patient care?

$\begin{array}{ll}\bigcirc & \text { Yes } \\ & \text { No }\end{array}$

2. What type of medical record do you use in your workplace?

Electronic health record

Paper medical record

Hybrid (both electronic and paper medical records)

\section{Section A. demographics and professional data}

1. What is your age?

$$
\begin{aligned}
& <25 \\
& 25-35 \\
& 36-45 \\
& 46-55 \\
& 56-65 \\
& >65
\end{aligned}
$$

2. Gender? 
- Female

3. Marital status?

$\begin{array}{ll}\bigcirc & \text { Single } \\ \bigcirc & \text { Married } \\ \bigcirc & \text { Widowed } \\ \bigcirc & \text { Divorced }\end{array}$

4. What is your nationality?

Saudi

Other:

5. What is your healthcare organization type?

Governmental

- Private

Other:

6. What is the level of care that your organization provides?

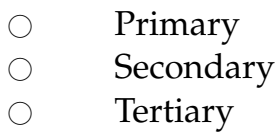

7. What is your healthcare profession?

Physician Skip to question 10

Nurse Skip to question 12

Pharmacist Skip to question 12

Other:

\section{Physician demographic and professional data:}

8. What is your specialty?

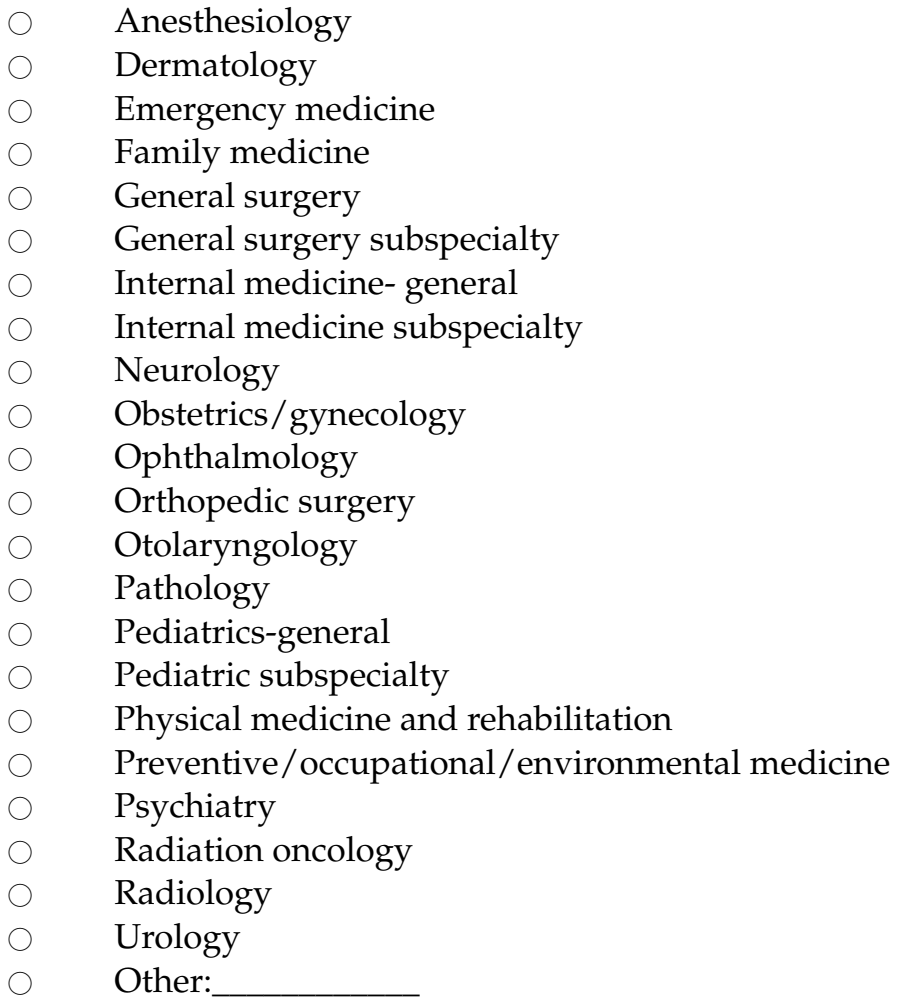

9. What is your job title? (Based on Saudi Commission for Health Specialists)

Resident

Registrar

Senior Registrar 
Consultant

Section A. demographics and professional data

10. Average working hours per week

$\begin{array}{ll} & <40 \\ 0 & 40-49 \\ 0 & 50-59 \\ 60-69 \\ 70-79 \\ 0 & \geq 80\end{array}$

11. What is the number of nights on call per week?

12. Are you directly involved in providing clinical care to suspected or confirmed patients with COVID-19?

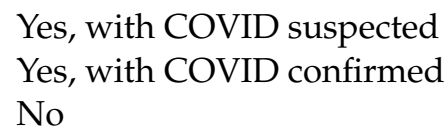

\section{Section B: Experience Using Electronic Health Record Systems}

13. How many years have you been using EHR? years

14. What is the name of the EHR system that you use in your organization?

$\begin{array}{ll}0 & \text { ACIBADEM } \\ 0 & \text { ACS (Qunatia) } \\ 0 & \text { Alert } \\ 0 & \text { Allscript (McKesson) } \\ 0 & \text { Bestcare } \\ 0 & \text { BETA CARE } \\ 0 & \text { Careware (ATS) } \\ 0 & \text { Cerner } \\ 0 & \text { Comprehensive eHealth solution } \\ 0 & \text { Cortex } \\ 0 & \text { Decent Care } \\ 0 & \text { DMS } \\ 0 & \text { iCare } \\ 0 & \text { In- house system } \\ \text { Intersystems (TrackCare) } \\ 0 & \text { Medica Plus } \\ 0 & \text { MedSys } \\ 0 & \text { Mini HIS } \\ 0 & \text { Oasis } \\ 0 & \text { Phoenix } \\ 0 & \text { Quadramed } \\ 0 & \text { Wipro } \\ 0 & \text { Vida } \\ 0 & \text { Other }\end{array}$

15. Rate your level of satisfaction with the EHR system at your organization?

Very dissatisfied

- Dissatisfied

- Neither satisfied nor dissatisfied

Satisfied

$\bigcirc \quad$ Very satisfied

16. Do you access your patients' EHR remotely from home?

Yes Skip to question 19

- No Skip to question 20 


\section{Access EHR remotely from home}

17. What is the reason for remote EHR use?

Check all that apply.

Unable to complete work during regular work hours

Have opportunity to work from home (e.g., to achieve work/life balance)

Other:

\section{Section C: Effect of EHR use}

18. Please indicate your level of agreement with the following statements that describe the effect of EHR use:

Mark only one oval per row.

\begin{tabular}{|c|c|c|c|c|c|}
\hline & $\begin{array}{l}\text { Strongly } \\
\text { disagree }\end{array}$ & Disagree & $\begin{array}{c}\text { Neither agree } \\
\text { nor disagree }\end{array}$ & Agree & $\begin{array}{l}\text { Strongly } \\
\text { agree }\end{array}$ \\
\hline $\begin{array}{l}\text { EHR use improves } \\
\text { communication among } \\
\text { physicians and staff in their } \\
\text { practice }\end{array}$ & & & & & \\
\hline
\end{tabular}

EHR use improves patient care

EHR use improves job satisfaction

EHR use improves clinical workflow

EHR use improve patient safety

Section D: Use of Electronic Health Record and technology tools during the COVID 19 pandemic

19. Telemedicine (virtual visit) with patients or with other healthcare practitioners:

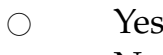

$\bigcirc \quad$ No

20. e- prescription:

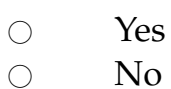

21. Messaging communication tools with patients (such as SMS or WhatsApp):

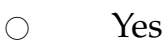

○ No

22. Electronic alert of COVID-19 cases (for example: electronic message stated that this patient is a COVID-19 case in the EHR):

$\bigcirc \quad$ Yes

23. Electronic referral of COVID-19 cases:

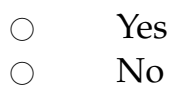

24. Ability to remotely access patients' EHRs from home after the COVID-19: 
Yes

No

25. Do you feel that using shared computer peripheral devices (such as the key boardand mouse at workplace) causes some kind of fear in becoming infected with the COVID$19 ?$

Yes

No

Maybe

26. Do you use other technology tools that support providing patient care during COVID19 pandemic?

Yes Skip to question 29

No Skip to question 30

Other technology that support providing patient care during COVID-19 pandemic:

27. Please specify other technology:

\section{Section E: About your health and wellbeing...}

28. The amount of time you spend using the EHR remotely at home is:

Excessive

Moderately high

Satisfactory

Modest

Minimal/none

29. Sufficiency of time for documentation at work is:

1 -Poor

2-Marginal

3-Satisfactory

4-Good

5-Optimal

30. Using the EHR adds frustration to my day:

- 1-Strongly disagree

2-Disagree

- 3-Neither agree nor disagree

4-Agree

5-Strongly agree

31. My proficiency with EHR use is:

1 -Poor

2-Marginal

3-Satisfactory

4-Good

5-Optimal

32. Using your own definition of "burnout", please circle one of the answers below:

a. I enjoy my work. I have no symptoms of burnout.

b. Occasionally I am under stress, and I don't always have as much energy as I once did, but I don't feel burned out.

c. I am definitely burning out and have one or more symptoms of burnout, such as physical and emotional exhaustion.

d. The symptoms of burnout that I'm experiencing won't go away. I think about frustrations at work a lot.

e. I feel completely burned out and often wonder if I can go on. I am at the point where I may need some changes or may need to seek some help.

33. Please indicate your level of agreement with the following statement: 
The burnout I am experiencing from the use of EHR and its associated features has increased due to the COVID-19 pandemic

$\begin{array}{ll}\bigcirc & \text { None } \\ \bigcirc & \text { Slight } \\ \bigcirc & \text { Moderate } \\ \bigcirc & \text { Likely } \\ \bigcirc & \text { Definitely }\end{array}$

Thank you for assisting us with our research

\section{References}

1. Vaishya, R.; Haleem, A.; Vaish, A.; Javaid, M. Emerging Technologies to Combat the COVID-19 Pandemic. J. Clin. Exp. Hepatol. 2020, 10, 409-411. [CrossRef] [PubMed]

2. Dabbagh, R.; Jamal, A.; Temsah, M.-H.; Masud, J.H.B.; Titi, M.; Amer, Y.; Alkubeyyer, M.; Alhazmi, T.; Baothman, F.; Hneiny, L. Machine learning models for predicting diagnosis or prognosis of COVID-19: A systematic review. Comput. Methods Programs Biomed. 2021, 205, 105993. [CrossRef]

3. Wang, C.J.; Ng, C.Y.; Brook, R.H. Response to COVID-19 in Taiwan: Big data analytics, new technology, and proactive testing. JAMA 2020, 323, 1341-1342. [CrossRef]

4. Portnoy, J.; Waller, M.; Elliott, T. Telemedicine in the Era of COVID-19. J. Allergy Clin. Immunol. Pract. 2020, 8, 1489-1491. [CrossRef]

5. Reeves, J.J.; Hollandsworth, H.M.; Torriani, F.J.; Taplitz, R.; Abeles, S.; Tai-Seale, M.; Millen, M.; Clay, B.J.; A Longhurst, C. Rapid response to COVID-19: Health informatics support for outbreak management in an academic health system. J. Am. Med Informatics Assoc. 2020, 27, 853-859. [CrossRef] [PubMed]

6. Russo, E.; Singh, H.; Gregory, M.E. Electronic Health Record Alert-Related Workload as a Predictor of Burnout in Primary Care Providers. Appl. Clin. Inform. 2017, 8, 686-697. [CrossRef]

7. Edwards, S.T.; Marino, M.; Balasubramanian, B.A.; Solberg, L.I.; Valenzuela, S.; Springer, R.; Stange, K.C.; Miller, W.L.; Kottke, T.E.; Perry, C.K.; et al. Burnout Among Physicians, Advanced Practice Clinicians and Staff in Smaller Primary Care Practices. J. Gen. Intern. Med. 2018, 33, 2138-2146. [CrossRef]

8. Huang, J.Z.; Han, M.F.; Luo, T.D.; Ren, A.K.; Zhou, X.P. Mental health survey of 230 medical staff in a tertiary infectious disease hospital for COVID-19. Chin. J. Ind. Hyg. Occup. Dis. 2020, 38, E001.

9. Lai, J.; Ma, S.; Wang, Y.; Cai, Z.; Hu, J.; Wei, N.; Wu, J.; Du, H.; Chen, T.; Li, R.; et al. Factors Associated With Mental Health Outcomes Among Health Care Workers Exposed to Coronavirus Disease 2019. JAMA Netw. Open 2020, 3, e203976. [CrossRef]

10. Downing, N.L.; Bates, D.W.; Longhurst, C.A. Physician Burnout in the Electronic Health Record Era: Are We Ignoring the Real Cause? Ann. Intern. Med. 2018, 169, 50-51. [CrossRef]

11. Dewa, C.S.; Loong, D.; Bonato, S.; Thanh, N.; Jacobs, P. How does burnout affect physician productivity? A systematic literature review. BMC Heal. Serv. Res. 2014, 14, 325. [CrossRef] [PubMed]

12. Agency for Healthcare and Quality. Physician Burnout. 2017. Available online: https://www.ahrq.gov/prevention/clinician/ ahrq-works/burnout/index.html (accessed on 29 March 2021).

13. COVID-19 Dashboard. Available online: https:/ / covid19.moh.gov.sa/ (accessed on 27 March 2021).

14. MOH. MOH Spokesman: Second Wave of COVID-19 Means Increase in Infections After Significant Decline. 2020. Available online: https://www.moh.gov.sa/en/Ministry/MediaCenter/News/Pages/News-2020-09-27-006.aspx (accessed on 27 April 2021).

15. Alsulimani, L.K.; Farhat, A.M.; Borah, R.A.; AlKhalifah, J.A.; Alyaseen, S.M.; Alghamdi, S.M.; Bajnaid, M.J. Health care worker burnout during the COVID-19 pandemic. Saudi Med. J. 2021, 42, 306-314. [CrossRef] [PubMed]

16. SCHS. About SCHS. Available online: https:/ /www.scfhs.org.sa/en/about/pages/organization.aspx (accessed on 29 March 2021).

17. Saudi Commission for Health Specialties. Daem Service. Available online: https://www.scfhs.org.sa/en/eservices/trainees/ Pages/TrainingGuidanceServiceDesc.aspx (accessed on 29 March 2021).

18. Gardner, R.L.; Cooper, E.; Haskell, J.; Harris, D.A.; Poplau, S.; Kroth, P.J.; Linzer, M. Physician stress and burnout: The impact of health information technology. J. Am. Med Inform. Assoc. 2018, 26, 106-114. [CrossRef] [PubMed]

19. Kroth, P.J.; Morioka-Douglas, N.; Veres, S.; Babbott, S.; Poplau, S.; Qeadan, F.; Parshall, C.; Corrigan, K.; Linzer, M. Association of Electronic Health Record Design and Use Factors With Clinician Stress and Burnout. JAMA Netw. Open 2019, 2, e199609. [CrossRef]

20. Shanafelt, T.D.; Dyrbye, L.N.; Sinsky, C.; Hasan, O.; Satele, D.; Sloan, J.; West, C.P. Relationship Between Clerical Burden and Characteristics of the Electronic Environment With Physician Burnout and Professional Satisfaction. Mayo Clin. Proc. 2016, 91, 836-848. [CrossRef]

21. Hassounah, M.; Raheel, H.; Alhefzi, M. Digital Response During the COVID-19 Pandemic in Saudi Arabia. J. Med Internet Res. 2020, 22, e19338. [CrossRef] 
22. Esmaeilzadeh, P.; Mirzaei, T. Using Electronic Health Records to Mitigate Workplace Burnout Among Clinicians During the COVID-19 Pandemic: Field Study in Iran. JMIR Med. Inform. 2021, 9, e28497. [CrossRef]

23. Wosik, J.; Fudim, M.; Cameron, B.; Gellad, Z.F.; Cho, A.; Phinney, D.; Curtis, S.; Roman, M.; Poon, E.G.; Ferranti, J.; et al. Telehealth transformation: COVID-19 and the rise of virtual care. J. Am. Med. Inform. Assoc. 2020, 27, 957-962. [CrossRef]

24. Eschenroeder, H.C.; Manzione, L.C.; Adler-Milstein, J.; Bice, C.; Cash, R.; Duda, C.; Joseph, C.; Lee, J.S.; Maneker, A.; A Poterack, K.; et al. Associations of physician burnout with organizational electronic health record support and after-hours charting. J. Am. Med. Inform. Assoc. 2021, 28, 960-966. [CrossRef]

25. A Peccoralo, L.; A Kaplan, C.; Pietrzak, R.H.; Charney, D.S.; Ripp, J.A. The impact of time spent on the electronic health record after work and of clerical work on burnout among clinical faculty. J. Am. Med. Inform. Assoc. 2021, 28, 938-947. [CrossRef]

26. Mann, D.M.; Chen, J.; Chunara, R.; Testa, P.; Nov, O. COVID-19 transforms health care through telemedicine: Evidence from the field. J. Am. Med. Inform. Assoc. 2020, 27, 1132-1135. [CrossRef]

27. Sasangohar, F.; Jones, S.L.; Masud, F.N.; Vahidy, F.S.; Kash, B.A. Provider Burnout and Fatigue During the COVID-19 Pandemic: Lessons Learned From a High-Volume Intensive Care Unit. Anesthesia Analg. 2020, 131, 106-111. [CrossRef]

28. Linzer, M.; Poplau, S. Building a sustainable primary care workforce: Where do we go from here? J. Am. Board Fam. Med. 2017, 30, 127-129. [CrossRef]

29. Schmoldt, R.A.; Freeborn, D.K.; Klevit, H.D. Physician burnout: Recommendations for HMO managers. HMO Pract. 1994, 8, 58-63.

30. Rohland, B.M.; Kruse, G.R.; Rohrer, J.E. Validation of a single-item measure of burnout against the Maslach Burnout Inventory among physicians. Stress Health 2004, 20, 75-79. [CrossRef]

31. Moore, C.G.; Carter, R.E.; Nietert, P.; Stewart, P.W. Recommendations for Planning Pilot Studies in Clinical and Translational Research. Clin. Transl. Sci. 2011, 4, 332-337. [CrossRef]

32. Harris, D.A.; Haskell, J.; Cooper, E.; Crouse, N.; Gardner, R. Estimating the association between burnout and electronic health record-related stress among advanced practice registered nurses. Appl. Nurs. Res. 2018, 43, 36-41. [CrossRef]

33. Schober, P.; Vetter, T.R. Logistic Regression in Medical Research. Anesthesia Analg. 2021, 132, 365-366. [CrossRef] [PubMed]

34. Poon, E.G.; Rosenbloom, S.T.; Zheng, K. Health information technology and clinician burnout: Current understanding, emerging solutions, and future directions. J. Am. Med. Inform. Assoc. 2021, 28, 895-898. [CrossRef] [PubMed]

35. Craig, K.J.T.; Willis, V.C.; Gruen, D.; Rhee, K.; Jackson, G.P. The burden of the digital environment: A systematic review on organization-directed workplace interventions to mitigate physician burnout. J. Am. Med. Inform. Assoc. 2021, 28, 985-997. [CrossRef]

36. Sharifi, M.; Asadi-Pooya, A.A.; Mousavi-Roknabadi, R.S. Burnout among Healthcare Providers of COVID-19; a Systematic Review of Epidemiology and Recommendations. Arch. Acad. Emerg. Med. 2020, 9, e7. [CrossRef]

37. Tajirian, T.; Stergiopoulos, V.; Strudwick, G.; Sequeira, L.; Sanches, M.; Kemp, J.; Ramamoorthi, K.; Zhang, T.; Jankowicz, D. The Influence of Electronic Health Record Use on Physician Burnout: Cross-Sectional Survey. J. Med Internet Res. 2020, 22, e19274. [CrossRef] [PubMed]

38. Collier, R. Electronic health records contributing to physician burnout. Can. Med Assoc. J. 2017, 189, E1405-E1406. [CrossRef]

39. Lourie, E.M.; Utidjian, L.H.; Ricci, M.F.; Webster, L.; Young, C.; Grenfell, S.M. Reducing electronic health record-related burnout in providers through a personalized efficiency improvement program. J. Am. Med. Inform. Assoc. 2020, 28, 931-937. [CrossRef] [PubMed]

40. Simpson, J.R.; Lin, C.-T.; Sieja, A.; Sillau, S.H.; Pell, J. Optimizing the electronic health record: An inpatient sprint addresses provider burnout and improves electronic health record satisfaction. J. Am. Med. Inform. Assoc. 2021, 28, 628-631. [CrossRef] [PubMed]

41. Chattopadhyay, I.; Davies, G.; Adhiyaman, V. The contributions of NHS healthcare workers who are shielding or working from home during COVID-19. Futur. Health J. 2020, 7, e57-e59. [CrossRef]

42. Temsah, M.H.; Al-Sohime, F.; Alamro, N.; Al-Eyadhy, A.; Al-Hasan, K.; Jamal, A.; Al-Maglouth, I.; Aljamaan, F.; Al Amri, M.; Barry, M.; et al. The psychological impact of COVID-19 pandemic on health care workers in a MERS-CoV endemic country. $J$ Infect. Public Health 2020, 13, 877-882. [CrossRef]

43. Burstyn, I.; Holt, K. A Cross-Sectional Survey of the Workplace Factors Contributing to Symptoms of Anxiety and Depression Among Nurses and Physicians During the First Wave of COVID-19 Pandemic in Two US Healthcare Systems. medRxiv 2021. [CrossRef]

44. Temsah, M.H.; Al Huzaimi, A.; Alrabiaah, A.; Alamro, N.; Al-Sohime, F.; Al-Eyadhy, A.; Alhasan, K.; Kari, J.A.; Alhaboob, A.; Alsalmi, A.; et al. Changes in healthcare workers' knowledge, attitudes, practices, and stress during the COVID-19 pandemic. Medicine 2021, 100, e25825. [CrossRef]

45. Zhongming, Z.; Wangqiang, Z.; Wei, L. Delta Variant, a Warning the COVID-19 Virus Is Getting 'Fitter and Faster'; M2 Presswire: Limpley Stoke, UK, 2021.

46. Puissant, S.P.; Gauthier, J.-M.; Van Oirbeek, R. The Contribution of Social Rank and Attachment Theory to Depression in a Non Clinical Sample of Adolescents. Span. J. Psychol. 2011, 14, 832-842. [CrossRef]

47. Alsubaie, S.; Temsah, M.H.; Al-Eyadhy, A.A.; Gossady, I.; Hasan, G.M.; Al-Rabiaah, A.; Jamal, A.A.; Alhaboob, A.A.; Alsohime, F.; Somily, A.M. Middle East Respiratory Syndrome Coronavirus epidemic impact on healthcare workers' risk perceptions, work and personal lives. J. Infect. Dev. Ctries. 2019, 13, 920-926. [CrossRef] [PubMed] 
48. Shah, K.; Chaudhari, G.; Kamrai, D.; Lail, A.; Patel, R.S. How essential is to focus on physician's health and burnout in coronavirus (COVID-19) pandemic? Cureus 2020, 12, e7538. [CrossRef] [PubMed]

49. Leslie, K. Death by 1000 Cuts': Medscape National Physician Burnout \& Suicide Report 2021. Medscape. 2021. Available online: https:/ / www.medscape.com/slideshow /2021-lifestyle-burnout-6013456 (accessed on 14 April 2021). 